\title{
NANORODS ZnO THIN FILM GROWN BY HYDROTHERMAL METHOD BASED PLANAR AND VERTICAL PD/ZnO SCHOTTKY DIODE CONFIGURATIONS
}

${ }^{*}$ Shahad T.Armoot ${ }^{1}$

1) M.Sc., Student Electrical Engineering Department, Mustansiriyah University, Baghdad, Iraq.

2) Asst. Prof. Dr. , Electrical Engineering Department, Mustansiriyah University, Baghdad, Iraq.
Ghusoon M. Ali²

\begin{abstract}
Manufacture and characterization of this paper for nanorods $\mathrm{ZnO}$ based planar and vertical Schottky diodes is presented. The $\mathrm{ZnO}$ thin film was grown on $\mathrm{n}$-Si$<100>$ substrates by the hydrothermal process. The performance of the planner $\mathrm{Pd} / \mathrm{ZnO} / \mathrm{Al}$ and $\mathrm{Pd} / \mathrm{ZnO} / \mathrm{Si} / \mathrm{Ti} / \mathrm{Al}$ vertical diode configurations were analyses and compared. Palladium, titanium, and aluminum have been deposited by thermal evaporation use masks of metal. The crystalline structure and surface morphological details for thin films for $\mathrm{ZnO}$ nanorods were described by using (XRD) and (SEM). By applying voltage range from $-2 \mathrm{~V}$ to $2 \mathrm{~V}$ Was measured (I-V) characteristics for two devices. The resulting data for both configurations show a typical exponential relationship between applied voltage and output current for the Schottky barrier diode. According to the measured I-V characteristics electrical parameters are extracted, for example, saturation current, ideality factor, barrier height, and rectification ratio. The simple low-cost nanorods Schottky diodes based on $\mathrm{ZnO}$ thin film make them a promising candidate in many electronics and optoelectronic applications.
\end{abstract}

\section{Introduction}

Schottky diode is an important device of the metal-semiconductor junctions, which classify as rectifying (Schottky) contact and a nonrectifying (Ohmic) contact [1]. In 1938, the Schottky barrier (SB) model explained by the theory of Schottky-Mott.
This the model assumed that the Schottky barrier formed based on the work function of metal $\left(\Phi_{m}\right)$ comparative to the electron affinity of the semiconductor $(X)[2,3]$. The Schottky barrier established with n-type semiconductor-metal contact, if the work function of metal $\left(\Phi_{m}\right)$ greater than the work function of semiconductor $\left(\Phi_{s}\right), \Phi_{m}>\Phi_{s}$ [3]. Zinc oxide is an intrinsical bandgap (3.37 eV) n-type wideband semiconductor. The unique electrical and optoelectrical properties of $\mathrm{ZnO}$ make it a promising material in many electronic and optoelectronic applications. $\mathrm{ZnO}$ is environmentally friendly, cheap, large exaction binding energy (60 $\mathrm{m} \mathrm{eV}$ ), easy to fabricate, and thermally stable. Besides, it can easily procedure different nanostructures such as nanorods, nanoparticles, nanowires, and nanotubes [4]. Nanostructures $\mathrm{ZnO}$ has been fabricated by different physical and chemical deposition techniques [5]. Hydrothermal aqueous solution deposition technique is a very simple and tailorable way to achieve nanostructures $\mathrm{ZnO}$ [6, 7]. The $\mathrm{ZnO}$ Schottky diodes are an effective device for gas sensors, field-effect transistors, 
light-emitting diodes, and photodetectors [8-10]. To achieve good quality $\mathrm{ZnO}$ Schottky diodes $\mathrm{ZnO}$ uses metals of low oxygen affinity (for example palladium, gold, and platinum), that prevent oxidation at the interface of metal/ZnO $[9,11]$. Many research papers on $\mathrm{Pd} / \mathrm{ZnO}$ Schottky contacts have been reported grown by various techniques [12]. In the present paper, the investigated of the fabrication Schottky contact configurations and characterization which planner $\mathrm{Pd} / \mathrm{ZnO} / \mathrm{Al}$ and the vertical $\mathrm{Pd} / \mathrm{ZnO} / \mathrm{Si} / \mathrm{Ti} / \mathrm{Al}$. A comparative study of two configurations is presented. This paper focuses on nanorods $\mathrm{ZnO}$ thin film that deposition by hydrothermal process. Furthermore, the thermal evaporation method is used to metalize $\mathrm{Pd}, \mathrm{Ti}$, and $\mathrm{Al}$ metal contact through the metal in the shape of rectangular $\left(2 \times 4 \mathrm{~mm}^{2}\right)$. For both configurations, electrical parameters were obtained using I-V characteristics. These performance parameters were ideality factor, saturation current, barrier height, and rectification ratio.

\section{Experiment Work}

In this section, the experimental work is presented. The $\mathrm{Si}$ substrate samples with a thickness of $380 \mu \mathrm{m}$ with the resistivity of 5 $\Omega . c m$. The Schottky diodes manufacture pass through five steps respectively; cleaning substrates, synthesize seed layer, growth $\mathrm{ZnO}$, mask fabrication, and metallization. Three different metals $\mathrm{Pd}, \mathrm{Al}$, and $\mathrm{Ti}$ are used in the metallization process. The fabrication steps are presented in detail in the following subsection.

\subsection{Cleaning and Synthesize of Seed layer:}

First, the n-Si <100> substrate 2-inch diameter is partition into four. Then clean it in two steps: The first step includes cleaning the substrates via isopropanol alcohol $\left(\mathrm{C}_{3} \mathrm{H}_{8} \mathrm{O}\right)$ to dispose of the organic remains by hand and immersed substrates in trichloroethylene ultrasonic bath for five minutes, then dip in acetone for one minute. The second step of the process, immersed substrates in a beaker contains $60 \mathrm{~mL}$ of hydrogen peroxide $\left(\mathrm{H}_{2} \mathrm{O}_{2}\right)$ and $40 \mathrm{ml}$ of sulphuric acid $\left(\mathrm{H}_{2} \mathrm{SO}_{4}\right)$ to cast off the organic residues. Later, the substrates cleaning in de-ionized water for five minutes. The substrates will be dried by a dry sterilized paper to take away deionized water [13]. After completing cleaning the samples, the thin seed layer deposited with a solgel spin coating technique on silicon substrates. The seed layer solution prepares of $\mathrm{ZnO}$ solution. The solution composite of $0.005 \mathrm{M}$ of zinc acetate dehydrates $\left(\mathrm{Zn}\left(\mathrm{CH}_{3} \mathrm{COO}\right)_{2} .2 \mathrm{H}_{2} \mathrm{O}\right)$ melt in $20 \mathrm{~mL}$ of isopropanol $\left(\mathrm{C}_{3} \mathrm{H}_{8} \mathrm{O}\right)$. The solution stirred for three hours at $50{ }^{\circ} \mathrm{C}$ to produce a homogeneous clear solution. The resultant solution was coated on silicon substrates via spin coater at the rate of spinning speed $3000 \mathrm{rpm}$ for $50 \mathrm{~s}$ at room temperature to prepare the $\mathrm{ZnO}$ seed layer. After that, the coated substrates were heated for 10 minutes at $100{ }^{\circ} \mathrm{C}$ to cast off the residual solution, and then the substrates had been cooled to room temperature. Then, substrates were annealed via oven (model: Huppert's Deluxe Furnace) at $300{ }^{\circ} \mathrm{C}$ for one hour [14].

\subsection{ZnO Nanorods Deposition Technique}

To grow the $\mathrm{ZnO}$ nanorods, the hydrothermal technique is utilized, after the seed layer has been formed. In the process of preparing the nanorods, a solution has contained two solutions mixed, the first solution contained $0.05 \mathrm{M}$ for Zinc nitrate Hexahydrate $\left(\mathrm{Zn}\left(\mathrm{NO}_{3}\right)_{2} \cdot 6 \mathrm{H}_{2} \mathrm{O}\right)$ at room temperature, mixed in $20 \mathrm{ml}$ deionized water which is stirred for 30 minutes. While the second one is containing $0.05 \quad \mathrm{M}$ Hexamethylenetetramine(HMTA) $\quad\left(\mathrm{C}_{6} \mathrm{H}_{12} \mathrm{~N}_{4}\right)$ solved in $20 \mathrm{ml}$ deionized water which is stirred for the same conditions. the weight of zinc nitrate and HMATA is; $0.297 \mathrm{~g}$ and $0.140 \mathrm{~g}$ respectively. The two solvent solutions are mixed and stirred for 20 minutes to be homogenous. The silicon substrates coated by the $\mathrm{ZnO}$ seeds layer are immersed in the prepared homogenous solution and kept in an autoclave. The autoclave is heated for $5 \mathrm{~h}$ at $90^{\circ} \mathrm{C}[14,15]$. 


\subsection{Contacts}

After the growth of the $\mathrm{ZnO}$ layer by the hydrothermal method, three metals aluminium, palladium, and titanium are utilized to metalized nanorods $\mathrm{ZnO} / \mathrm{Si}$ samples via masks. The metallization is done via a molybdenum mask with dimensions of $20 \mathrm{~mm} \times 20 \mathrm{~mm}$ which has a rectangular hole of $4 \mathrm{~mm} \times 2 \mathrm{~mm}$ which uses thermal vacuum evaporation (model: VSAAMA VAC) system. (Al) and (Pd) is deposited at the top of thin $\mathrm{ZnO}$ films are Schottky electrodes thickness $200 \mathrm{~nm}$ and distance between $100 \mu \mathrm{m}$. It stabilized at the top of the $\mathrm{ZnO}$ semiconductor. The thickness of (Ti) and (Al) are $100 \mathrm{~nm}$ and $200 \mathrm{~nm}$ respectively as layers on the bottom of the sample. The scheme for vertical and planar fabricated devices is shown in Figure.1.

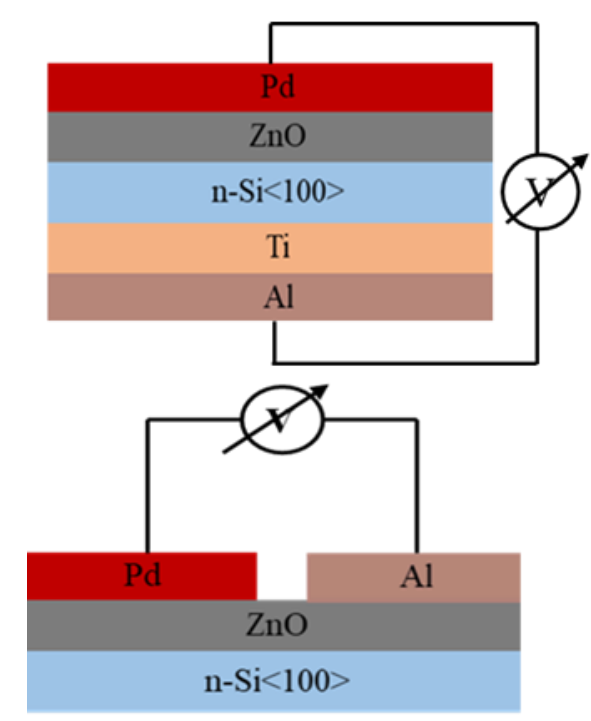

Figure.1 representation of schematic diagram for (a) vertical and (b) planar Schottky diode

\section{Characterization}

The $\mathrm{ZnO}$ thin film morphology and the crystal structures are explored by the X-Ray Diffraction (XRD) and Scanning Electron Microscope (SEM) techniques. The structural characteristics for prepared samples are calculated using the XRD technique including crystallinity and lattice parameters also defects [16]. The specifications of the X-ray diffractometer device are (typical: $\mathrm{XRD}-6000$, lab X) with $2 \theta$ starting at $\left(20^{\circ}\right.$ to $\left.60^{\circ}\right)$ and $\mathrm{Cu} \mathrm{K} \alpha$ radiation $(\lambda=1.5405 \AA)$. by utilizing Keithley (SCS-4200) device to calculated characteristics of $\mathrm{I}-\mathrm{V}$ are produced from fabricated diode Schottky configurations which are a planar $(\mathrm{Pd} / \mathrm{ZnO} / \mathrm{Al})$ and a vertical $(\mathrm{Pd} / \mathrm{ZnO} / \mathrm{Si} / \mathrm{Ti} / \mathrm{Al})$. The range of applied voltages at room temperature varies from $-2 \mathrm{~V}$ to $2 \mathrm{~V}$, with step $0.1 \mathrm{~V}$.

\section{Experimental results and discussion}

\section{1. crystalline surface structure and morphology for $\mathrm{ZnO}$ Thin Film}

The inset of Fig. 2, shows the XRD pattern with an SEM image for the $\mathrm{ZnO}$ layer deposited on nsilicon <100> substrates. The SEM image demonstrates that the hexagonal nanorods are the main form of nanostructure of $\mathrm{ZnO}$ patterns. The nanorods arranged perpendicular to the surface of the substrate as clusters in different directions. Nanorods have different lengths and diameters, the average diameters are approximately $116 \mathrm{~nm}$, whereas the length of the nanorods is approximately $2 \mu \mathrm{m}$. The SEM examination is compatible with the XRD pattern which has multiple peaks. This is evidence of $\mathrm{ZnO}$ nanorods that are settled in more than one direction. XRD absolute intensity (crystallinity) was determined from the strongest diffraction peak. In the Fig. Y. shown, the XRD pattern appears in which four peaks corresponding to the hexagonal planes $\mathrm{ZnO}$ crystal (100), (002), (101) and (110), which are shown in 31.8, 34.52, 36.26 and 56.63 respectively [17]. By using Scherer equation determine crystallite size (D) in (nm)[18] :

$\mathrm{D}=\frac{\mathrm{K}_{\mathrm{C}} \lambda}{\beta \cos \theta}$

Where $\mathrm{Kc}$ is a Scherer constant equal to 0.9 , The wavelength $(\lambda)$ for an $\mathrm{x}$-ray source equal to 1.5406 (nanometer), the FWHM $(\beta)$ (radians) is the full width of a maximum half and the $\theta$ is a maximum position (radians). 


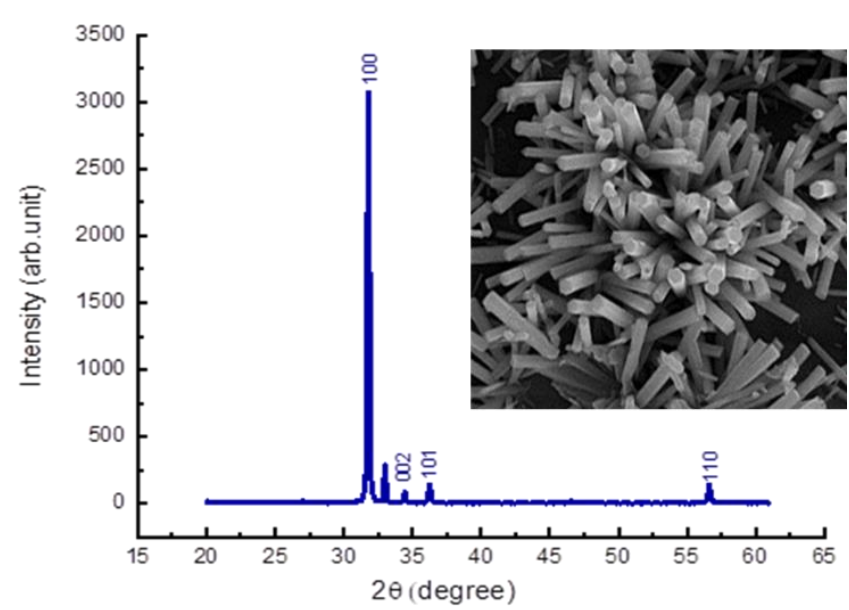

Figure. 2 XRD pattern with the SEM image for the $\mathrm{ZnO}$ layer Precipitated by the hydrothermal process above silicon substrates.

\subsection{The Electrical Characteristics and Performance for $\mathrm{Pd} / \mathrm{ZnO}$ Schottky contact Fabricated.}

Fig .3 and Fig .4 show I-V Characteristics I- of vertical $\mathrm{Pd} / \mathrm{ZnO} / \mathrm{Si} / \mathrm{Ti} / \mathrm{Al}$ and Planar $\mathrm{Pd} /$ $\mathrm{ZnO} / \mathrm{Al}$ Schottky contacts were determined by experimentally testing. The performance I-V characteristics parameters extracted obtained from is calculated according to the thermionic emission theory.

Rectification ratio $R R$ was measurement by $\left(\mathrm{I}_{\mathrm{F}} / \mathrm{I}_{\mathrm{R}}\right)$ at $\pm 2 \mathrm{~V}$ ( $\mathrm{I}_{\mathrm{F}}$ forward current at $\mathrm{V}=2 \mathrm{~V}$ and $I_{R}$ reverse current at $\mathrm{V}=-2 \mathrm{~V}$ ), its obtained 79.13 for vertical and 137.58 for planar Schottky contact. The difference in $\mathrm{RR}$ is due to an improvement characteristic of planar than vertical and the lower reverse current of a planar comparison with the vertical Schottky barrier diode. The resulting data can be analyzed in the general by using the Eq. (2) $[3,19]$ :

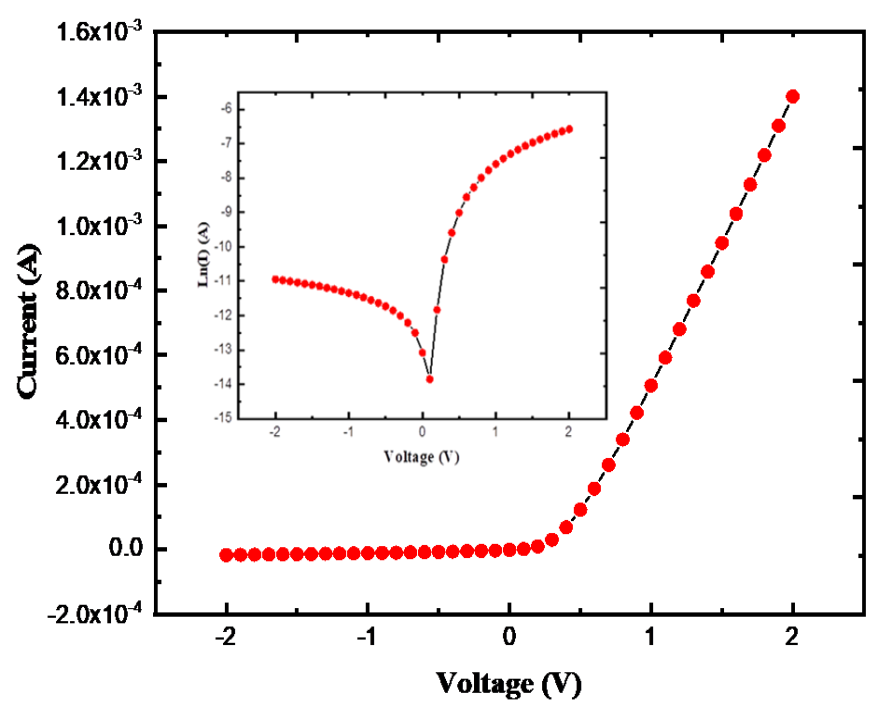

Figurer.3 I-V characteristics for the vertical Schottky contact linear, and semi-log curve.

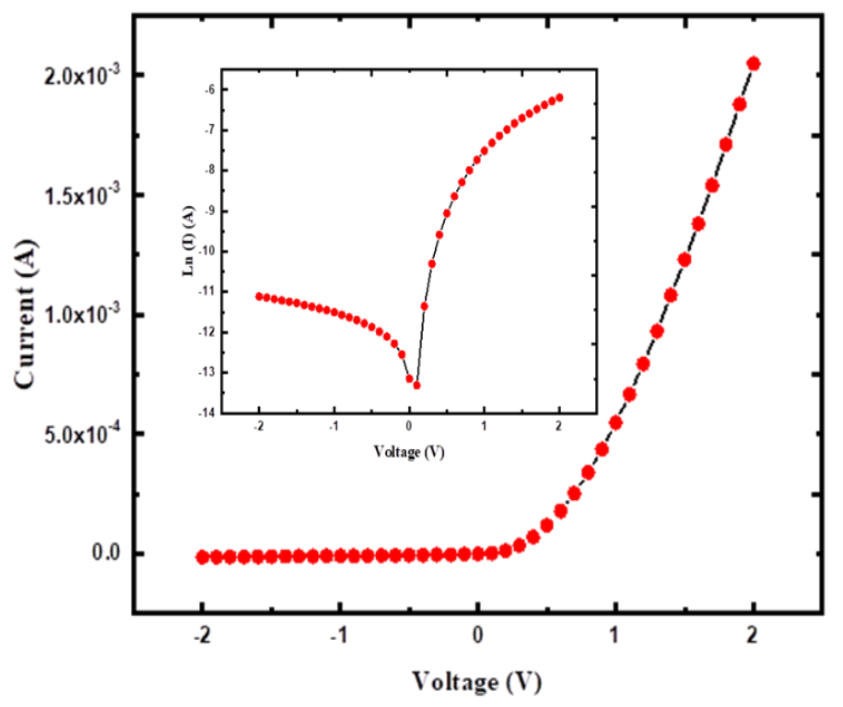

Figure.4 I-V Characteristics of planar Schottky contact linear, and semi-log curve.

$I=\left[A A^{*} T^{2} \exp \left(\frac{-q \Phi_{B}}{k T}\right)\right]\left[\exp \left(\frac{q v}{n k T}\right)-1\right]$

$A$ is the contact area of Schottky diode, $A^{*}$ is the effective constant of Richardson, (theoretically, $\mathrm{A}^{*}=32 \mathrm{~cm}^{-2} \mathrm{~K}^{-2}$ value of $\mathrm{ZnO}$ using $\left(\mathrm{m}^{*}=\right.$ $0.27 \mathrm{mo})$ ), $\mathrm{k}$ is constant of Boltzmann, $\mathrm{T}$ is the absolute temperature, $\mathrm{n}$ is the ideality factor, $\Phi_{B}$ is a barrier height, $\mathrm{q}$ is an electron charge. The equation can be approximated by applying the condition $\left(\exp \left(\frac{q V}{n k T}\right) \gg 1\right.$ ) [20]. 


$$
\begin{aligned}
I_{S} & =A A^{*} T^{2} \exp \left(\frac{-q \Phi_{B}}{\mathrm{k} T}\right) \\
\mathrm{I} & =\mathrm{I}_{\mathrm{s}}\left(\frac{\mathrm{qv}}{\mathrm{nkT}}\right)
\end{aligned}
$$

The saturation current Is calculating from intercept Ln (I) vs $\mathrm{V}$ with Y-axis under forwarding bias at $\mathrm{V}=0$ for a semi-log curve. The saturation current is found to be $5.01 \times 10^{-7} \mathrm{~A}$ and $1.42 \times 10^{-6} \mathrm{~A}$ for vertical and planar diodes respectively. The Ideality factor(n) equation is obtained by deriving equation (4), where the derivative is equal to slope value for $\mathrm{Ln}$ (I) vs V, according to Eq.5, the ideality factor is calculated [21]:

$$
\frac{\mathrm{d} \ln (\mathrm{I})}{\mathrm{dV}}=\frac{\mathrm{q}}{\mathrm{nkT}} \quad \mathrm{n}=\frac{\mathrm{q}}{\mathrm{kT}} \times \frac{1}{\mathrm{slop}}
$$

Barrier Height $(\mathrm{BH})$ can be determinate by using equation (6) [11]:

$$
\Phi_{B}=\frac{k T}{q} \ln \left(\frac{A A^{*} T^{2}}{I_{S}}\right)
$$

The values of the ideality factor are found to be, 3.24 and 4.83 for vertical and planar Schottky diode, respectively. The barriers heights are estimated to be $0.94 \mathrm{eV}$ and $0.93 \mathrm{eV}$ for vertical and planar Schottky diode, respectively. Calculates theoretical barrier height from Schottky- Mott by using Eq $q \Phi_{\mathrm{B}}=q\left(\Phi_{S}-\chi\right)$ is found to be $1.42 \mathrm{eV}$, where the work function $\left(\mathrm{q} \Phi_{S}\right)$ for $\mathrm{Pd}$ is equal to $5.17 \mathrm{eV}$, and the electron affinity for $\mathrm{ZnO}(q \chi)$ is $3.7 \mathrm{eV}[6,22]$. The barriers heights which are calculated from the experimental work are less than theoretical. This indicates that the interface states cannot be neglected; the interface states also affect the ideality factor. The ideality factors for fabricated devices are more than unity for an ideal diode that attributed to many reasons. The mechanism in which the current was transferred through the $\mathrm{ZnO}$ thin film which forms the basis of the Schottky diode was not only the thermionic emission. The other mechanism such as recombination carrier recombination, inhomogeneity of barrier, uniform distribution of carriers at interfaces, or the mechanism of transport tunnelling and the surface states must be considered [13]. The presence of interface oxide at the $\mathrm{ZnO}$ and palladium layer during technological operations in the manufacturing of semiconductor devices. Where $\mathrm{ZnO}$ is readily creating interface layers with one or two monolayers of thickness between 200 to $400 \mathrm{~nm}$ (Adsorbed oxygen, hydroxide, heat, etc..), which results in an average surface level of the surface for $\mathrm{ZnO}$. These status lead to high-value of $\mathrm{n}$ and non-ideal Schottky diode [23, 24].

\section{Conclusion}

In this paper, we fabricated and characterized by the vertical and planar $\mathrm{Pd} / \mathrm{ZnO} \mathrm{NR}$ thin-film Schottky diodes are presented. The performance parameters estimated and analyzed. The $\mathrm{ZnO}$ nanorods thin film has grown with the hydrothermal technique above $\mathrm{n}-\mathrm{Si}<100>$ substrates. XRD and SEM test results confirmed indicated that $\mathrm{ZnO}$ nanorods have high surface quality and structural characteristics. Applying the thermionic emission theory, the electrical parameters were calculated and analyzed for both devices. We found the performance parameters divergence from the ideal thermionic emission theory, concluding that the thermionic emission theory cannot govern the current transport mechanism alone. The electrical parameters estimated for two devices found to be in good agreement with those reported by other researchers.

\section{Acknowledgements}

Electrical Department / Faculty of Engineering / Mustansiriyah University support this work

\section{Conflict of interest}

There is no conflict of interest.

\section{References}

1. W. Mtangi, "Electrical characterization of $\mathrm{ZnO}$ and metal $\mathrm{ZnO}$ contacts," University of Pretoria, 2010. 
2. W. J. N. Schottky. (1938)."Semi-conductor theory in barrier layers," vol. 26, no. 843, p. 280, 1938.

3. S. M. Sze and K. K. Ng. (2006). Physics of semiconductor devices. John Wiley \& sons.

4. M. Willander, O. Nur, N. Bano, and K. J. N. J. o. P. Sultana. (2009). "Zinc oxide nanorodbased heterostructures on solid and soft substrates for white-light-emitting diode applications," vol. 11, no. 12, p. 125020.

5. S. Faraz, H. Noor, M. Asghar, M. Willander, and Q.-u. Wahab. (2009). "Modeling and simulations of $\mathrm{Pd} / \mathrm{n}-\mathrm{ZnO}$ Schottky diode and its comparison with measurements," in Advanced Materials Research, vol. 79, pp. 1317-1320: Trans Tech Publ.

6. Q. $\mathrm{Gu}$ et al. (2008). "Au/n-ZnO rectifying contact fabricated with hydrogen peroxide pretreatment," vol. 103, no. 9, p. 093706.

7. B. Coppa et al. (2005). "Structural, microstructural, and electrical properties of gold films and Schottky contacts on remote plasma-cleaned, n-type $\mathrm{ZnO} \quad\{0001\}$ surfaces," vol. 97, no. 10, p. 103517.

8. A. B. Yadav, R. Shankar, R. Kumar, A. Pandey, and S. Jit. (2013). "Analysis of temperature-dependent IV characteristics of $\mathrm{Pd} / \mathrm{ZnO} / \mathrm{n}-\mathrm{Si}$ Schottky diode by sol-gel method,". in Proc. Int. conf. on Microelectronics, Communications and Renewable Energy, pp. 1-4: IEEE.

9. T. Varma, C. Periasamy, D. J. S. Boolchandani, and Microstructures. (2017). "Performance analyses of Schottky diodes with $\mathrm{Au} / \mathrm{Pd}$ contacts on $\mathrm{n}-\mathrm{ZnO}$ thin films as UV detectors," vol. 112, pp. 151-163.

10. D. Somvanshi and S. J. I. E. D. L. Jit. (2014). "Effects of Sn and Zn Seed Layers on the Electrical Characteristics of $\mathrm{Pd} / \mathrm{ZnO}$ ThinFilm Schottky Diodes Grown on n-Si Substrates," vol. 35, no. 9, pp. 945-947.

11. D. Somvanshi, S. J. J. o. N. Jit, and Optoelectronics. (2014)."Analysis of I-V characteristics of $\mathrm{Pd} / \mathrm{ZnO}$ thin film/n-Si Schottky diodes with series resistance," vol. 9, no. 1, pp. 21-26.

12. L. Rajan, C. Periasamy, and V. J. P. i. S. Sahula. (2016). "Electrical characterization of $\mathrm{Au} / \mathrm{ZnO}$ thin film Schottky diode on a silicon substrate," vol. 8, pp. 66-68.

13. G. M. Ali, J. C. Moore, A. K. Kadhim, C. J. S. (2014). Thompson, and A. A. Physical, "Electrical and optical effects of $\mathrm{Pd}$ microplates embedded in $\mathrm{ZnO}$ thin film based MSM UV photodetectors: A comparative study," vol. 209, pp. 16-23.

14. G. M. J. J. o. A. Ali and Compounds. (2020). "Performance analysis of planar Schottky photodiode based on nanostructured $\mathrm{ZnO}$ thin film grown by three different techniques," p. 154859.

15. N. Yu et al. (2014). "Synthesis of $\mathrm{ZnO}$ film on P-GaN/Si (111) by one-step hydrothermal method," vol. 550, pp. 206-209.

16. R. Kohli. (2012). "Methods for monitoring and measuring the cleanliness of surfaces," in Developments in Surface Contamination and Cleaning: Elsevier, pp. 107-178.

17. D. Somvanshi and S. Jit. (2014). "Electrical characteristics of $\mathrm{Pd} / \mathrm{ZnO}$ nanowires (NWs)-based Schottky diodes grown on $\mathrm{Zn}$ seed layer coated n-Si substrates," Proc. Int. conf. on Emerging Electronics (ICEE), pp. 1-4: IEEE.

18. N. Shakti and P. J. A. P. R. Gupta. (2010). "Structural and optical properties of sol-gel prepared $\mathrm{ZnO}$ thin film," vol. 2, no. 1, p. 19.

19. G. M. Ali, A. Dwivedi, S. Singh, and P. J. p. s. s. c. Chakrabarti. (2010)."Interface properties and junction behaviour of $\mathrm{Pd}$ contact on $\mathrm{ZnO}$ thin film grown by a vacuum deposition technique," vol. 7, no. 2, pp. 252255.

20. R. K. Pandey, A. K. Singh, and R. J. A. A. Prakash. (2013)."Enhancement in 
performance of polycarbazole-graphene nanocomposite Schottky diode," vol. 3, no. 12, p. 122120.

21. Y. Kumar, H. Kumr, G. Rawat, C. Kumar, B. N. Pal, and S. Jit. (2016). "Electrical and optical characteristics of $\mathrm{Pd} / \mathrm{ZnO}$ Quantum dots based Schottky Photodiode on n-Si," in 2016 IEEE International Symposium on Nanoelectronic and Information Systems (iNIS), pp. 214-217: IEEE.

22. P. N. M. Ngoepe. (2013)."Optoelectronic characterisation of AlGaN based Schottky barrier diodes," the University of Pretoria.

23. B. Coppa et al. (2004). "In situ cleaning and characterization of oxygen-and zincterminated, n-type, $\mathrm{ZnO}\{0001\}$ surfaces," vol. 95, no. 10, pp. 5856-5864.

24. N. Zhang, K. Yu, L. Li, and Z. J. A. s. s. Zhu. (2008). "Investigation of electrical and ammonia sensing characteristics of Schottky barrier diode based on a single ultra-long $\mathrm{ZnO}$ nanorod," vol. 254, no. 18, pp. 5736-5740. 